\title{
Correspondence
}

\section{Cervical fracture and cervical cord injury during anger management course}

Spinal Cord (2005) 43, 392-393. doi:10.1038/sj.sc.3101711; Published online 1 March 2005

A 35-year-old businessman was brought into hospital by ambulance complaining of neck pain. He had been attending an anger management course during which the participants were encouraged to express their pent up emotion either verbally or physically. In an attempt to relieve his suppressed anger the patient 'head-butted' the floor with his forehead from a standing position. He immediately complained of severe neck pain, could not get up and was witnessed to have involuntary spasms in both arms.

On examination in the accident and emergency department, he was found to be quadra paretic with flaccid arreflexia of the lower limbs and spastic hyperreflexia of the upper limbs. He was in urinary retention and had decreased anal tone.

Cervical spine X-rays demonstrated a wedge fracture of C5 and MRI revealed a cord injury at this level (Figure 1).

The following day he underwent major spinal surgery comprising anterior C5 vertebrectomy with insertion of a titanium cage as well as with anterior and posterolateral mass plates C4-C6 (Figure 2).

At 2 days postoperatively he started to regain upper limb power, and within 10 days some lower limb function. Prior to discharge from the rehabilitation unit 10 weeks postinjury, the patient was able to walk with a stick and had normal bowel and bladder function.

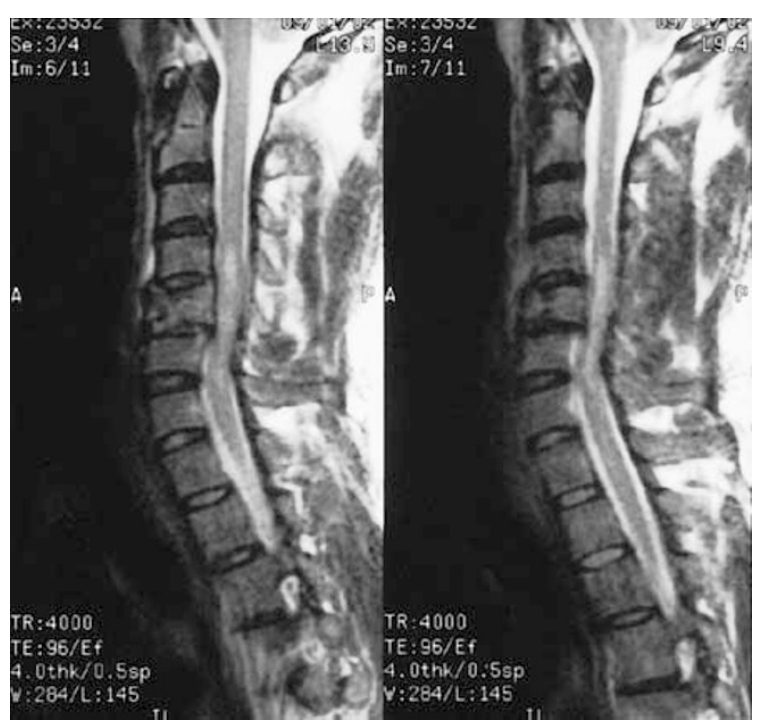

Figure 1 Sagittal MRI cervical-spine showing fracture and cord injury

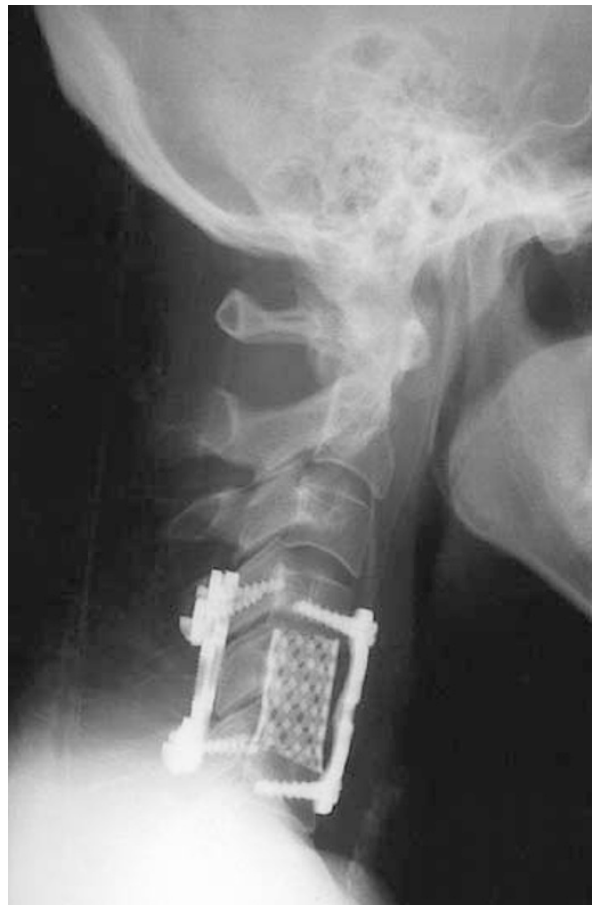

Figure 2 Postoperation lateral cervical-spine X-ray showing the fixation

\section{Comment}

Anger is an emotional state that varies in intensity from mild irritation to intense fury and rage. And like other emotions, it is accompanied by physiological and biological changes. Uncontrolled and violent outbursts of anger are on the increase whether at home, on the road or in the work environment. Anxiety and anger are hazardous to health. ${ }^{1}$ Stress and anger can increase a person's susceptibility to illness. ${ }^{2}$

Anxiety management training (AMT) was the term originally given to the cognitive-behavioral intervention for anxiety management developed in $1971 .^{3}$ Controlled studies have supported the efficacy of AMT for anger control. ${ }^{4}$ Anger management classes have been run for a number of years in the UK and are becoming increasingly popular with both individuals and organisations aiming to relieve workplace stress for employees.

This patient sustained a C5 vertebral fracture with subsequent tetraplegia in one of these sessions. Spinal surgery and rehabilitation enabled him to regain independence in all activities of daily living and mobility 
by time of discharge, 10 weeks later. This case illustrates a significant self-inflicted injury sustained in the controlled environment of the anger management program.

Anyone can become angry - that is so easy. But, to become angry with the right person, to the right degree, at the right time, for the right purpose, and in the right way - that is not so easy (Aristotle 384-322 BC).

R Mobasheri ${ }^{1}$ and A Cope ${ }^{1}$

${ }^{1}$ Flat 30 Beechcroft, Galsworthy Road, Kingston, UK

\section{References}

1 Suinn RM. The teffrible twos - anger and anxiety. Hazards to your health. Am Psychol 2001; 56: 27-36.

2 Siegel J, Brown J. A prospective study of stressful circumstances, illness symptoms, and depressed mood among adolescents. Dev Psychol 1988; 24: 715-721.

3 Suinn R, Richardson F. Anxiety management training: a non-specific behaviour therapy program for anxiety control. Behav Ther 1971; 2: 498-512.

4 Deffenbacher J, Huff M, Lynch R, Oetting E, Salvatore N. Characteristics and treatment of high-anger drivers. J Couns Psychol 2000; 47: 5-17. 